\title{
Programa Nacional de Imunizações: o desafio do acesso universal no Século XXI
}

O Programa Nacional de Imunizações (PNI) foi criado em 1973, fruto de uma iniciativa que, em um contexto político adverso, contou, em sua concepção, com a convergência de sanitaristas comprometidos com a saúde da população e de uma burocracia pública nacionalista. Seu nascimento ocorria como desdobramento natural do sucesso da Campanha de Erradicação da Varíola (CEV) e da crescente preocupação com a disponibilidade de imunobiológicos como fator importante para a constituição de um sistema nacional de saúde, no contexto de projeto autoritário de construção da nação'

Alguns elementos permitem, no entanto, destacar que, em vez de um fato fortuito na história, a emergência deste programa refletia o crescente enraizamento de um movimento na sociedade para garantir o acesso à saúde. Já na Lei 6.259 de 1975 se estabelecia a gratuidade para as vacinas consideradas obrigatórias. $\mathrm{Na}$ fase inicial do Programa, as vacinas contra difteria, tétano e coqueluche (DTP), poliomielite, tuberculose (BCG) e sarampo passaram a ser aplicadas de modo sistemático mediante calendários de vacinação.

O PNI já possuía alguns dos alicerces dos princípios defendidos na VIII Conferência Nacional de Saúde que culminaram na criação do SUS na Constituição de 1988. O crescente número de vacinas incorporadas ao Programa deveria garantir o acesso universal gratuito, constituía um direito compartilhado por toda população e requeria uma ação integrada no território, envolvendo diferentes níveis de complexidade tecnológica. Representavam uma apropriação do conhecimento em saúde pela sociedade, tendo a participação importante de instituições científicas públicas, com destaque para a Fundação Oswaldo Cruz e para o Instituto Butantan.

Pode-se afirmar que esta matriz embrionária que articulava ciência, tecnologia e acesso universal se realizou com plenitude após a conformação do SUS, sendo uma das marcas mais reconhecidas e exemplares ${ }^{2}$ da possibilidade de constituição, nos trópicos, do maior sistema universal do mundo em termos populacionais. No presente, no calendário de vacinação de 2020, está prevista a oferta de 18 vacinas, cobrindo mais de 20 doenças infecciosas. Todo rol de vacinas essenciais disponíveis em termos internacionais é ofertado para a população.

A marca que alia a ciência, a tecnologia e a produção nacional deu sustentação a este Programa. Sem uma base produtiva e tecnológica nacional o acesso universal não teria sido possível ${ }^{3}$. O PNI, de fato, marcou uma profunda inovação tecnológica e social no Brasil, aliando as forças do conhecimento e da produção nacional aos desafios do acesso universal.

No contexto atual, em que a vacina para o novo coronavírus torna-se essencial para a vida e para a saída da crise, novos desafios se colocam para a continuidade e a superação dialética desta história de sucesso. $\mathrm{O}$ domínio sobre o conhecimento e a inovação torna-se fator decisivo para as chances do SUS do Futuro. O conhecimento e a ciência nunca foram tão centrais e decisivos para garantir o acesso universal para nossa população. As respostas aos desafios da saúde pública, tão bem expressas no PNI, têm que ser reinventadas. Aliar soberania, ciência e saúde, como na tradição original do PNI, em um contexto democrático pautado pelo direito ao conhecimento, ao desenvolvimento e à vida, é o grande desafio para o Século XXI. Mais uma vez, o PNI deve se constituir em uma semente transformadora para um futuro equânime... que tem pressa.

Carlos Augusto Grabois Gadelha (https://orcid.org/0000-0002-9148-8819) ${ }^{1}$

${ }^{1}$ Coordenação das Ações de Prospecção da Presidência, Escola Nacional de Saúde Pública Sérgio Arouca, Fiocruz. Rio de Janeiro RJ Brasil.

\section{Referências}

1. Temporão JG. O Programa Nacional de Imunizações (PNI): origens e desenvolvimento. História, Ciências, Saúde-Manguinhos 2003; 10(Supl. 2):601-617.

2. Organização Pan-Americana da Saúde (OPAS). Relatório 30 anos de SUS, que SUS para 2030? Brasília: OPAS; 2018.

3. Gadelha CAG, Braga PSC, Montenegro KBM, Cesário BB. Acesso a vacinas no Brasil no contexto da dinâmica global do Complexo Econômico-Industrial da Saúde. Cad Saude Publica 2020; 36(Supl. 2):e00154519. 